\title{
Eu-doped $\mathrm{K}_{0.5} \mathrm{Na}_{0.5} \mathrm{NbO}_{3}$-(Ba,Sr)TiO ${ }_{3}$ : A novel lead-free luminescent ferroelectric transparent ceramic with reversible photochromism*
}

\author{
Jinfeng $\operatorname{Lin}^{\dagger}$, Xiao $\mathrm{Wu}^{\dagger}, \S$, Cong $\operatorname{Lin}^{\dagger}$, Tengfei $\operatorname{Lin}^{\dagger}$ and Yaojin Wang ${ }^{\ddagger}$ \\ ${ }^{\dagger}$ College of Materials Science and Engineering \\ Fuzhou University, Fuzhou 350108, P. R. China \\ ${ }^{\ddagger}$ School of Materials Science and Engineering \\ Nanjing University of Science and Technology \\ Nanjing 210094, P. R. China \\ §uxiao@fzu.edu.cn
}

Received 15 August 2019; Revised 15 September 2019; Accepted 19 September 2019; Published 21 October 2019

\begin{abstract}
Photochromic (PC) luminescent ferroelectric materials have aroused great interest because of their potential applications in optical information memories, optical switches and bio-imaging. However, those materials are basically opaque. In this work, we prepared a PC luminescent $\mathrm{K}_{0.5} \mathrm{Na}_{0.5} \mathrm{NbO}_{3}$-based ferroelectric transparent ceramic by modifying with $\mathrm{Eu}^{3+}, \mathrm{Ba}^{2+}, \mathrm{Ti}^{4+}$ and $\mathrm{Sr}^{2+}$, which not only have good optical transmittances $(\sim 60 \%$ at $900 \mathrm{~nm})$, moderate ferroelectric properties and down-conversion photoluminescence (PL) properties, but also exhibit reversible PC behavior. After the illumination by xenon lamp, the colors of the ceramics change from pale green to gray, and then reversibly recover to their initial state via thermal stimulus $\left(200^{\circ} \mathrm{C}\right.$ for $\left.10 \mathrm{~min}\right)$. Interestingly, both the optical transmittances and PL intensities can be effectively tailored by controlling the PC reaction process. The results suggest that the ferroelectric transparent ceramics are promising for the modulation of photoenergy and the design of optoelectronic devices.
\end{abstract}

Keywords: Ferroelectric ceramics; optical transmittance; Eu-KNNBST; photochromism; photoluminescence.

\section{Introduction}

With the explosion of information and technology in "photonic" industry, photoelectric devices based on optoelectronic materials have attracted extensive interest for the applications of information storage, photoswitches, optical sensing and smart windows. ${ }^{1}$ Photochromic (PC) materials have been widely studied with regards to their ability of reflectivity and photoluminescence (PL) modulations in response to external stimulation. Photochromism phenomenon describes a process where the color of specimen can be changed (i.e., the coloration state and the decoloration state) via alternating visible/ultraviolet light irradiation, heat, or even electric field. $^{2,3}$ Among all the PC materials, inorganic solid oxides own outstanding thermal stability, mechanical strength and chemical resistance. ${ }^{4,5}$ To date, RE-doped inorganic ferroelectrics, such as $\mathrm{Na}_{0.5} \mathrm{Bi}_{2.5} \mathrm{Nb}_{2} \mathrm{O}_{9},{ }^{6} \mathrm{Na}_{0.5} \mathrm{Bi}_{0.5} \mathrm{TiO}_{3}$ (NBT) ${ }^{5}$ and $\left(\mathrm{K}_{0.5} \mathrm{Na}_{0.5}\right) \mathrm{NbO}_{3}(\mathrm{KNN}){ }^{7}$ have been found to exhibit reversible PL modulation behavior based on PC reaction. However, the functionality of them is restricted as the ferroelectric performance can hardly be connected with the PC characteristics and the underlying PC mechanism is ambiguous. Hence, it is of great significance to explore new ferroelectrics with excellent PC properties and investigate the intrinsic kinetic process of $\mathrm{PC}$ reaction.
Environment-friendly lead-free KNN-based ceramics have been regarded as the most promising alternative to toxic lead-based piezoelectric materials, owing to their moderate dielectric constant, optimum piezoelectric response and good ferroelectricity ${ }^{8-13}$ Recently, RE-doped KNN ceramics have been verified to have both PC and PL modulation behaviors induced by vacancy-related defects (e.g., $\mathrm{K} / \mathrm{Na} / \mathrm{O}$ vacancies), ${ }^{2-7}$ expanding the electrical applications to optoelectronic areas. Generally, pure KNN ceramics own poor relative density ( $\sim 95 \%)$, low symmetry structure (orthorhombic phase) and large grain size $(1-2 \mu \mathrm{m}) \cdot{ }^{14}$ After using highly purified raw chemicals, tailoring the host composition and doping suitable ions, $\mathrm{KNN}$-based ceramics could be fabricated into transparent ones, such as $(1-x)\left(\mathrm{K}_{0.5} \mathrm{Na}_{0.5}\right) \mathrm{O}_{3}-x \mathrm{Ba}$ $\left(\mathrm{Sc}_{0.5} \mathrm{Nb}_{0.5}\right) \mathrm{O}_{3} \quad(\mathrm{KNN}-x \mathrm{BSN}){ }^{15} \quad\left(\mathrm{~K}_{0.5} \mathrm{Na}_{0.5}\right)_{1-x} \mathrm{Li}_{x} \mathrm{Nb}_{1-x^{-}}$ $\mathrm{Bi}_{x} \mathrm{O}_{3}(\mathrm{KNN}-x \mathrm{LB})^{16}$ and $(1-x)\left(\mathrm{K}_{0.5} \mathrm{Na}_{0.5}\right) \mathrm{NbO}_{3}-x \mathrm{SrTiO}_{3}$ $(\mathrm{KNN}-x \mathrm{ST}),{ }^{17}$ exhibiting high relative density (over 98\%), high symmetry (cubic or cubic-like phase) and fine grain size (below $500 \mathrm{~nm}$ ). In addition, RE (e.g., Er or Ho)-doped KNN-based transparent ceramics are promising due to the coexistence of superior di-/piezo-/ferro-electric, optical, upconversion PL and electro-optic properties, which can be adopted in interdisciplinary studies. It is well known that KNN-based materials have potential in the application of

\footnotetext{
*This paper was originally submitted to the special issue on lead-free piezo/ferroelectric materials.
}

This is an Open Access article published by World Scientific Publishing Company. It is distributed under the terms of the Creative Commons Attribution 4.0 (CC BY) License which permits use, distribution and reproduction in any medium, provided the original work is properly cited. 
ferroelectric storage. It can be predicted that if the PC behavior can be realized in KNN-based ferroelectric transparent ceramics, the information storage will boost because of the combination of both ferroelectric and optical memories in the single entity.

Lately, our group first discovered the photochromism phenomenon in Er-doped $\left(\mathrm{K}_{0.5} \mathrm{Na}_{0.5}\right){ }_{0.95} \mathrm{Li}_{0.05} \mathrm{Nb}_{0.95} \mathrm{Bi}_{0.05} \mathrm{O}_{3}$ transparent ceramic, whose optical transmittance and upconversion PL intensity can be effectively modulated through reversible PC reaction. ${ }^{18}$ Furthermore, it is necessary to develop other KNN-based transparent ceramics with PC behavior in the purpose of providing theoretical guidance for the development of luminescent ferroelectrics. In this work, a novel transparent ceramic, Eu-doped $\mathrm{K}_{0.5} \mathrm{Na}_{0.5} \mathrm{NbO}_{3}-(\mathrm{Ba}, \mathrm{Sr})$ $\mathrm{TiO}_{3}$, possessing high optical transmittance and good downconversion PL performance, is prepared by traditional solid-state synthesis. The results show that after the illumination by xenon lamp, the material not only owns decreased optical transmittance, but also exhibits remarkable PL modulation.

\section{Experimental}

According to the designed formula of $x$ mol. $\% \mathrm{Eu}^{3+}$-doped $0.91 \mathrm{~K}_{0.5} \mathrm{Na}_{0.5} \mathrm{NbO}_{3}-0.09 \mathrm{BaSrTiO}_{3}$ (abbreviated as $x \mathrm{Eu}-$ KNNBST, $x=0.25,0.5,1)$, the ceramics were prepared by the solid-state reaction. Analytical-grade $\mathrm{K}_{2} \mathrm{CO}_{3}(99.99 \%)$, $\mathrm{Na}_{2} \mathrm{CO}_{3}$ (99.8\%), $\mathrm{SrCO}_{3}$ (99.8\%), $\mathrm{Nb}_{2} \mathrm{O}_{5}$ (99.5\%), $\mathrm{Ti}_{2} \mathrm{O}_{3}$ $(99.8 \%), \mathrm{BaCO}_{3}(99.95 \%)$ and $\mathrm{Eu}_{2} \mathrm{O}_{3}(99.99 \%)$ raw chemicals were dried and weighed first. For each composition, the weighed powders were ball-milled for $12 \mathrm{~h}$ in ethanol, dried at $80^{\circ} \mathrm{C}$, calcined at $850^{\circ} \mathrm{C}$ for $4 \mathrm{~h}$ and secondarily ballmilled for $10 \mathrm{~h}$. After that, the obtained powders were mixed thoroughly with a $5 \mathrm{wt}$ \% polyvinyl alcohol (PVA) binder solution and uniaxially pressed into disks (with the diameter of $12 \mathrm{~mm}$ and thickness of $1 \mathrm{~mm}$ ) under the pressure of $\sim 300 \mathrm{MPa}$. To completely burn out PVA and remove pores, the obtained pellets were heated to $800^{\circ} \mathrm{C}$ for $2 \mathrm{~h}$ at a slow rate of $0.5^{\circ} \mathrm{C} / \mathrm{min}$. Subsequently, the disk samples were finally sintered at $1205^{\circ} \mathrm{C}$ for $4 \mathrm{~h}$ in air for densification. All the as-prepared ceramics were polished to a thickness of $\sim 0.3 \mathrm{~mm}$ to measure the optical and PL properties.

The optical transmittances of the ceramics were measured in the range of 300-950 $\mathrm{nm}$ by an ultraviolet-visible-infrared (UV-Vis-IR) spectrophotometer (PerkinElmer Lambda 950). The phase structure was characterized by X-ray diffraction (XRD, Rigaku Ultima III) with $\mathrm{Cu} K_{\alpha}$ radiation. The surface microstructures and element maps were performed by field emission scanning electron microscope (SEM, Zeiss Supra 55) and Energy Dispersive Spectrometer (EDS). The corresponding grain size distribution was determined by measuring 150 grains from the SEM micrographs using the linear intercept method based on the "Nano Measurer" software. The polarization-electric field $(\mathrm{P}-\mathrm{E})$ hysteresis loops were performed at $100 \mathrm{~Hz}$ by a ferroelectric test system (TF Analyzer 2000, aixACCT). The PL spectra were obtained using a spectro-fluorometer (FluoroMax-4, HORIBA). The xenon lamp (PerkinElmer CEL-PE300L-3A, 300 W) with the wavelength ranging from $200 \mathrm{~nm}$ to $1100 \mathrm{~nm}$ was used as the light illumination source for the PC reaction.

\section{Result and Discussions}

\subsection{Optical transmittance}

The optical transmittances $(T)$ of the $x$ Eu-KNNBST transparent ceramics are plotted in Fig. 1, ranging from $300 \mathrm{~nm}$ to $850 \mathrm{~nm}$. With the increase of $\mathrm{Eu}^{3+}$ content $(x)$, the $T$ values just change slightly, suggesting that Eu-doping does not affect the transmittances of samples. As the wavelength increases, $T$ rises rapidly at $400 \mathrm{~nm}$ and then gradually increases until reaching almost maximum in the near-infrared (NIR) region $(900 \mathrm{~nm})$. All the samples exhibit good optical transmittances from visible to NIR range, giving the $T$ values of $\sim 35 \%$ at $500 \mathrm{~nm}$ (green region), $\sim 45 \%$ at $600 \mathrm{~nm}$ (red region) and $\sim 60 \%$ at $900 \mathrm{~nm}$ (NIR region). The results are consistent with the optical transparencies of sample photographs, as shown in the set of Fig. 1. Not only Chinese characters under the samples are clearly visible, but the background objects (e.g., mobile phone case and stove) can be seen through the transparent ceramics. The $T$ values of $x \mathrm{Eu}-\mathrm{KNNBST}$ are higher than those of non-RE doped $\mathrm{KNN}$-based transparent ceramics, including $\mathrm{KNN}-x \mathrm{ST},{ }^{17}(1-x) \mathrm{KNN}-x \operatorname{Sr}\left(\mathrm{Al}_{0.5} \mathrm{Nb}_{0.5}\right) \mathrm{O}_{3}{ }^{19}$ and $(1-x) \mathrm{KNN}-$ $x \mathrm{Sr}\left(\mathrm{Mg}_{1 / 3} \mathrm{Nb}_{2 / 3}\right) \mathrm{O}_{3},{ }^{20}$ and are comparable to that of $\mathrm{KNN}$ $x$ LB. ${ }^{15}$ And novel transparent ceramics can be adopted in various functional applications, such as optical-electrical and magneto-optical integrated devices. ${ }^{21}$

\subsection{Phase and microstructure}

To uncover the reason of high optical transparency of $x \mathrm{Eu}$ KNNBST ceramics, phase structures and microstructures

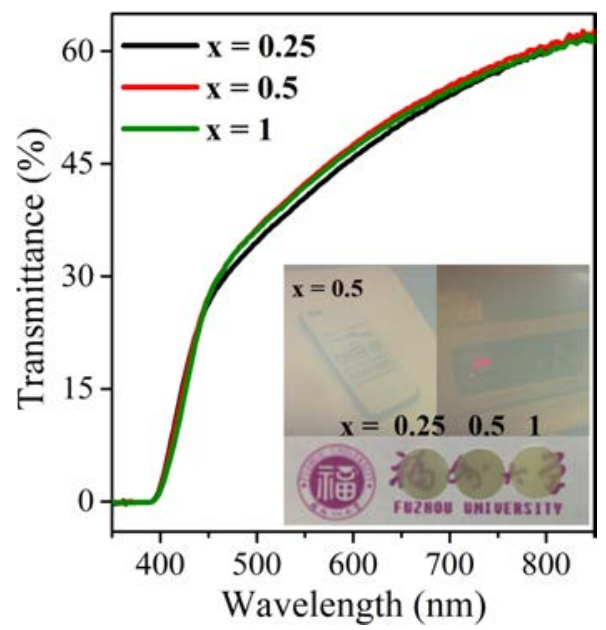

Fig. 1. Optical transmittance spectra of the $x$ Eu-KNNBST transparent ceramics and the photographs of the ceramics with the thickness of $\sim 0.3 \mathrm{~mm}$ (the insets). 


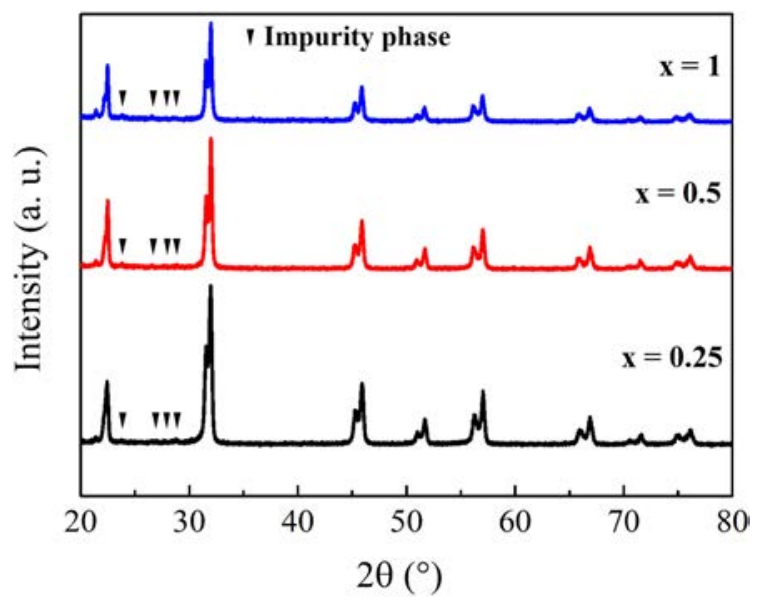

Fig. 2. XRD patterns of the $x \mathrm{Eu}-\mathrm{KNNBST}$ transparent ceramics.

were investigated. Figure 2 shows the XRD patterns of $x \mathrm{Eu}$ KNNBST with different $\mathrm{Eu}^{3+}$ contents. All the samples possess almost pure perovskite structure (except for a small amount of impurity phases in the range of $20-30^{\circ}$ as marked in Fig. 2), suggesting that the modified ions (i.e., $\mathrm{Eu}^{3+}, \mathrm{Ba}^{2+}$, $\mathrm{Sr}^{2+}$ and $\mathrm{Ti}^{4+}$ ) have diffused into the $\mathrm{KNN}$ host lattice. According to the ionic radius of $\mathrm{K}^{+}(1.51 \AA$, coordination number $\mathrm{CN}=12), \mathrm{Na}^{+}(1.18 \AA, \mathrm{CN}=12), \mathrm{Eu}^{3+}(0.96 \AA$, $\mathrm{CN}=12), \mathrm{Sr}^{2+}(1.326 \AA, \mathrm{CN}=12), \mathrm{Ba}^{2+}(1.68 \AA$, $\mathrm{CN}=12), \mathrm{Nb}^{5+}(0.69 \AA, \mathrm{CN}=6)$ and $\mathrm{Ti}^{4+}(0.64 \AA$, $\mathrm{CN}=6), \mathrm{Eu}^{3+} / \mathrm{Sr}^{2+}$ may preferentially replace the Na-site, $\mathrm{Ba}^{2+}$ may occupy the $\mathrm{K}$-site, while $\mathrm{Ti}^{4+}$ is more likely to substitute for the $\mathrm{Nb}$-site. For the diffraction angle at around $45^{\circ}$, the first diffraction peak is lower than the second one, which indicates that the ceramics have a tetragonal phase structure at room temperature. Additionally, the generation of impurity phases can be due to the volatilization of alkali metal ions $\left(\mathrm{K}^{+} / \mathrm{Na}^{+}\right)$in the high-temperature sintering environment (i.e., $1205^{\circ} \mathrm{C}$ for $4 \mathrm{~h}$ ) and then the stoichiometric deviation. $^{22-24}$ From the perspective of crystal symmetry, compared with the orthorhombic phase of pure $\mathrm{KNN}$, the tetragonal phase of $x \mathrm{Eu}$-KNNBST is closer to cubic one, benefitting in reducing optical anisotropy and light scattering. Therefore, the optical transmittances of the $x$ Eu-KNNBST ceramics significantly improve.

Figure 3 shows the SEM micrographs of free surfaces of the $x$ Eu-KNNBST ceramics. All the samples have cubical grains although some pores inevitably exist. The columnar maps of grain size distributions are shown in the inset of Fig. 3, giving the average sizes of $137 \mathrm{~nm}$ (for $x=0.25$ ), $164 \mathrm{~nm}$ (for $x=0.5$ ) and $180 \mathrm{~nm}$ (for $x=1$ ). The ceramics own superior homogeneity as the grains of each sample are evenly distributed. Induced by the modification of the doping ions $\mathrm{Eu}^{3+}, \mathrm{Ba}^{2+}, \mathrm{Ti}^{4+}, \mathrm{Sr}^{2+}$, the grain sizes of $x \mathrm{Eu}-$ KNNBST are much smaller than pure KNN ceramics $(1-2 \mu \mathrm{m}) .{ }^{10}$ The reduction of grains should be attributed to the donor/acceptor doping effect of the ions. According to the XRD analysis that $\mathrm{Eu}^{3+} / \mathrm{Sr}^{2+} / \mathrm{Ba}^{2+}$ may preferentially
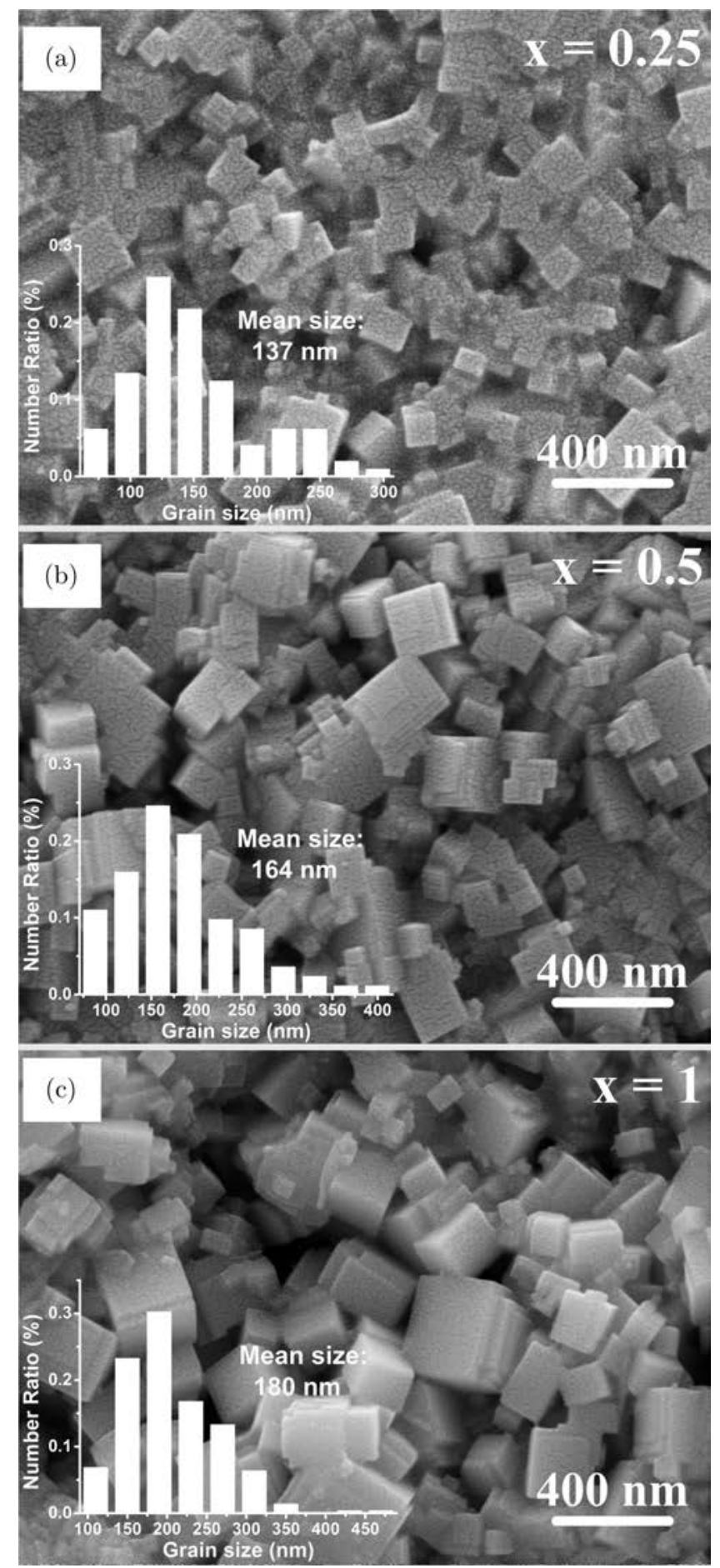

Fig. 3. SEM micrographs of the $x$ Eu-KNNBST transparent ceramics, (a) $x=0.25$, (b) $x=0.5$ and (c) $x=1$. The inset of (a), (b) and (c) show the columnar map of the grain size distribution and mean size of the $x \mathrm{Eu}-\mathrm{KNNBST}$ transparent ceramics.

occupy the site of $\mathrm{Na}^{+}$or $\mathrm{K}^{+}$(donor doping) and $\mathrm{Ti}^{4+}$ probably substitute for the site of $\mathrm{Nb}^{5+}$ (acceptor doping), both cation and oxygen vacancies (i.e., $\mathrm{K} / \mathrm{Na} / \mathrm{O}$ vacancies) will be created in the KNN matrix to maintain the charge 
Table 1. Densities $(\rho)$, theory densities (TD) and relative densities (RD) of the $x \mathrm{Eu}$-KNNBST transparent ceramics.

\begin{tabular}{lccc}
\hline Sample & $\rho\left(\mathrm{g} / \mathrm{cm}^{-3}\right)$ & $\mathrm{TD}\left(\mathrm{g} / \mathrm{cm}^{-3}\right)$ & $\mathrm{RD}(\%)$ \\
\hline$x=0.25$ & 4.636 & 4.832 & 95.95 \\
$x=0.5$ & 4.644 & 4.831 & 96.11 \\
$x=1$ & 4.659 & 4.83 & 96.45 \\
\hline
\end{tabular}

balance. These vacancies are inclined to accumulate at the grain boundaries during grain growth, pinning the movement of grain boundaries and inhibiting the grain growth. ${ }^{19,20,25}$ Consequently, the grain sizes of $x$ Eu-KNNBST ceramics greatly reduce. In addition, appropriate amount of rare earth (RE) oxides can serve as sintering additive to promote grain growth and improve the density of ceramics. ${ }^{19,26}$ As increasing the $\mathrm{Eu}^{3+}$ content, the grains marginally become larger (Figs. 3(a)-3(c)) and relative density slightly increases from $95.95 \%(x=0.25)$ to $96.45 \%(x=1)$ (Table 1). Furthermore, it can be observed that the mean grain size of each sample is far smaller than the wavelength of visible light. Thus, the scattering of the incident light by grain boundary can be effectively reduced, resulting in improving the optical transmittance. To analyze the elements, EDS analysis of the typical sample ( $x$ Eu-KNNBST with $x=0.5$ ) is shown in
Fig. 4. All the elements (K, Na, Nb, O, Eu, Ba, Sr, Ti) can be observed and homogeneously distributed in the KNN-based matrix (Figs. 4(b) and 4(c)). However, it can be seen that the atomic percentage of $\mathrm{K}$ to $\mathrm{Nb}(\mathrm{K} / \mathrm{Nb})$ is $\sim 37 \%$ (Fig. 4(d)) and deviates from the theoretical ratio (i.e., 50\%), indicating that the $\mathrm{K}$ element has volatilized under high sintering temperature $\left(1205^{\circ} \mathrm{C}\right)$. While the atomic percentage of $\mathrm{Na}$ to $\mathrm{Nb}(\mathrm{Na} /$ $\mathrm{Nb}$ ) is close to $50 \%$, suggesting that the volatilization of $\mathrm{Na}$ element is low at $1205^{\circ} \mathrm{C}$. Combining with the XRD (Fig. 2) and SEM (Fig. 3) results, it can be concluded that highoptical transmittances of the $x \mathrm{Eu}$-KNNBST ceramics are attributed to fine and uniform grains $(<200 \mathrm{~nm})$, dense structure as well as improved crystal symmetry.

\subsection{Ferroelectric properties}

In order to investigate the electrical properties of the $x \mathrm{Eu}$ KNNBST ceramics, P-E hysteresis loops were measured at $100 \mathrm{~Hz}$ under different electric fields, as shown in Fig. 5. The shapes of P-E loops of the $x$ Eu-KNNBST ceramics are almost saturated. With increasing the electric fields, the maximum polarization $\left(P_{\max }\right)$ and remanent polarization $\left(P_{r}\right)$ of them gradually increase. Interestingly, as $x$ increases, the dielectric breakdown of the $x \mathrm{Eu}$-KNNBST ceramics increases, from $46 \mathrm{kV} / \mathrm{cm}$ for $x=0.25$ to $107 \mathrm{kV} / \mathrm{cm}$ for $x=1$, which is
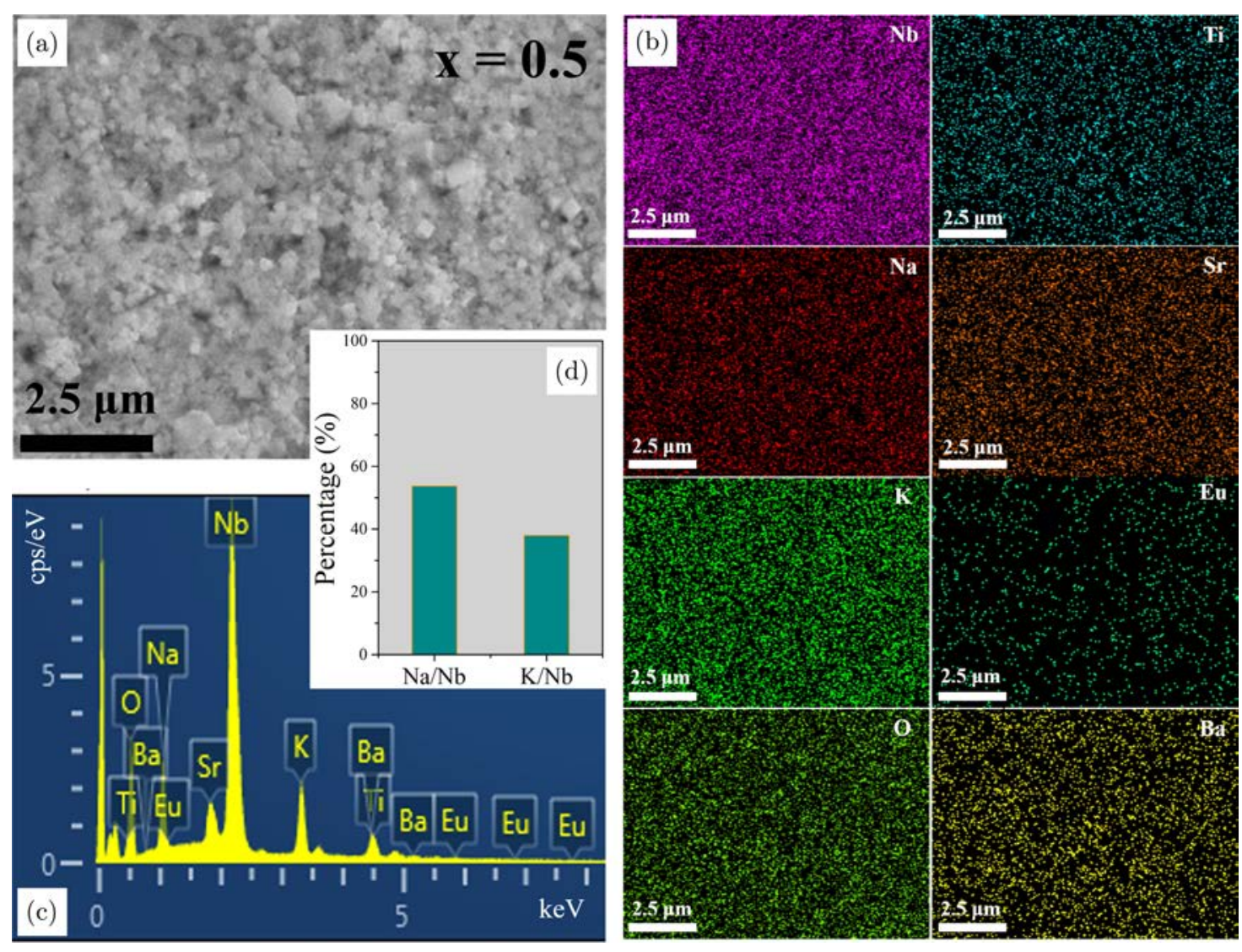

Fig. 4. Element analysis of the typical sample $x$ Eu-KNNBST with $x=0.5$, (a) SEM images, (b) and (c) K, Na, Nb, O, Ti, Sr, Eu, Ba elemental mappings and EDS spectrum, respectively, (d) $\mathrm{Na} / \mathrm{Nb}$ and $\mathrm{K} / \mathrm{Nb}$ atomic ratio. 


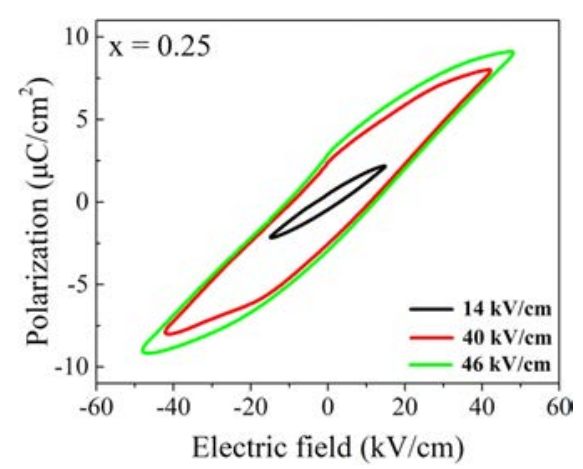

(a)

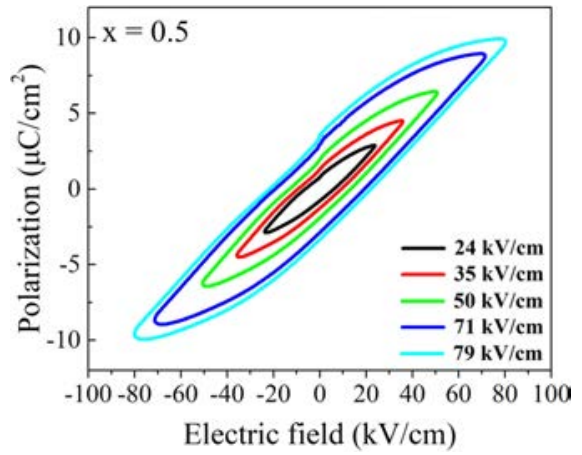

(b)

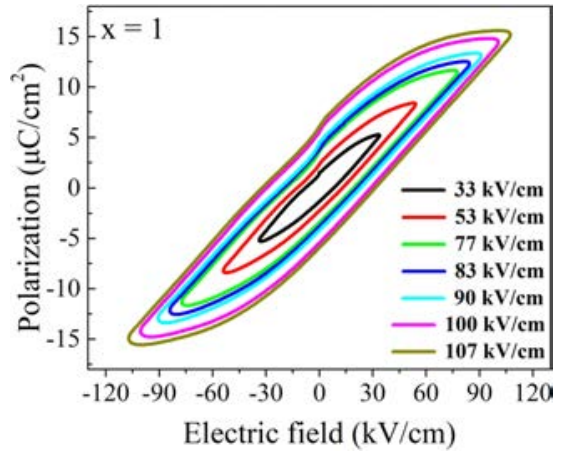

(c)

Fig. 5. The P-E curves $(100 \mathrm{~Hz})$ of the $x$ Eu-KNNBST transparent ceramics.

mainly related to the densities of the samples (Table 1). The ceramics with higher relative densities possess higher breakdown field strength. The $P_{r}$ values are $3.18 \mu \mathrm{C} / \mathrm{cm}^{2}$ (for $x=0.25$ ), $3.87 \mu \mathrm{C} / \mathrm{cm}^{2}$ (for $x=0.5$ ) and $6.66 \mu \mathrm{C} / \mathrm{cm}^{2}$ (for $x=1$ ). The above results indicate that the ceramics have moderate ferroelectric properties, which are related to the doping content of $\mathrm{Eu}^{3+}$.

\subsection{PL properties}

Figure 6 shows the PL excitation (PLE) spectrum monitored at the 592-nm emission and the PL emission spectra excited by $407 \mathrm{~nm}$, taking $x$ Eu-KNNBST with $x=1$ as the representative example. The excitation spectrum consists of three strong absorptions bands centered at $407 \mathrm{~nm}, 460 \mathrm{~nm}$ and $530 \mathrm{~nm}$, coming from the ${ }^{7} \mathrm{~F}_{0} \rightarrow{ }^{5} \mathrm{~L}_{6},{ }^{7} \mathrm{~F}_{0} \rightarrow{ }^{5} \mathrm{D}_{2}$ and ${ }^{7} \mathrm{~F}_{0} \rightarrow{ }^{5} \mathrm{D}_{1}$ transitions of $\mathrm{Eu}^{3+}$, respectively. ${ }^{27}$ Among them, the blue emission peak at $465 \mathrm{~nm}$ is the strongest. Upon the excitation at $407 \mathrm{~nm}$, the emission spectrum exhibits one weak emission band at $578 \mathrm{~nm}$, and two strong ones centered at $592 \mathrm{~nm}$ and $615 \mathrm{~nm}$, respectively. According to the energy level scheme of $\mathrm{Eu}^{3+}$ (inset of Fig. 6), these emission bands are mainly from the characteristic $f-f$ transition emissions of $\mathrm{Eu}^{3+}$ at $578\left({ }^{5} \mathrm{D}_{0} \rightarrow{ }^{7} \mathrm{~F}_{0}\right), 592\left({ }^{5} \mathrm{D}_{0} \rightarrow{ }^{7} \mathrm{~F}_{1}\right)$ and $615 \mathrm{~nm}$ $\left({ }^{5} \mathrm{D}_{0} \rightarrow{ }^{7} \mathrm{~F}_{2}\right) .{ }^{6}$ Figure 7 shows the room temperature PL emission spectra of the $x$ Eu-KNNBST ceramics with different $\mathrm{Eu}^{3+}$ concentrations. Three main emission bands with distinct intensities make $x$ Eu-KNNBST emit reddish-orange light. The PL intensity gradually increases with $x$, indicating more effective energy transfer process at shorter inter-distance between two $\mathrm{Eu}^{3+}$ ions as $x$ increases (below the quenching concentration, e.g., $x, \leq 0.01$ in $x$ Eu-KNNBST).

\subsection{Transmittance modulations by $P C$ reactions}

When illuminated by a $300-\mathrm{W}$ xenon lamp (with the wavelengths of $200-1100 \mathrm{~nm}$ ) for $2 \mathrm{~min}$, the colors of $x \mathrm{Eu}-$ KNNBST transparent ceramics become darker and their optical transparencies seem worse (Fig. 8(a)). And after thermal stimulus at $200^{\circ} \mathrm{C}$ for $10 \mathrm{~min}$, both colors and transparencies can recover to the initial state, exhibiting excellent reversible capacity. The phenomenon is called reversible photochromism, based on vacancy-related defects caused by volatilization of alkali metal ions (i.e., $\mathrm{K}^{+}$and $\mathrm{Na}^{+}$) and ion

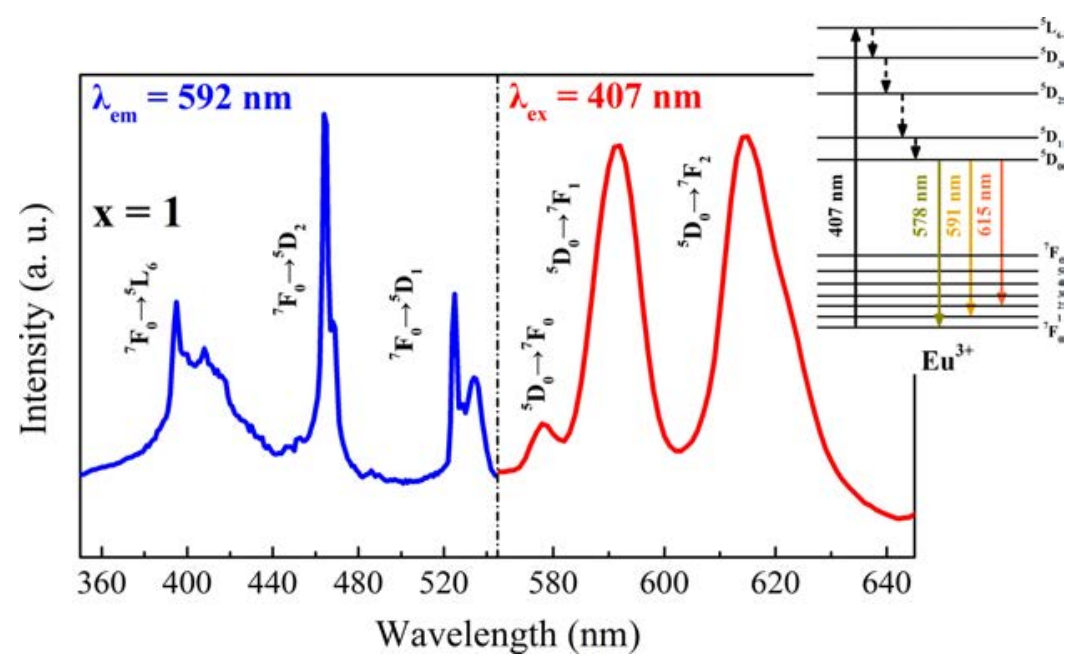

Fig. 6. The PLE and PL spectra of 1Eu-KNNBST monitored at $592 \mathrm{~nm}$ and $407 \mathrm{~nm}$, the inset is the energy level diagram of Eu ${ }^{3+}$. 


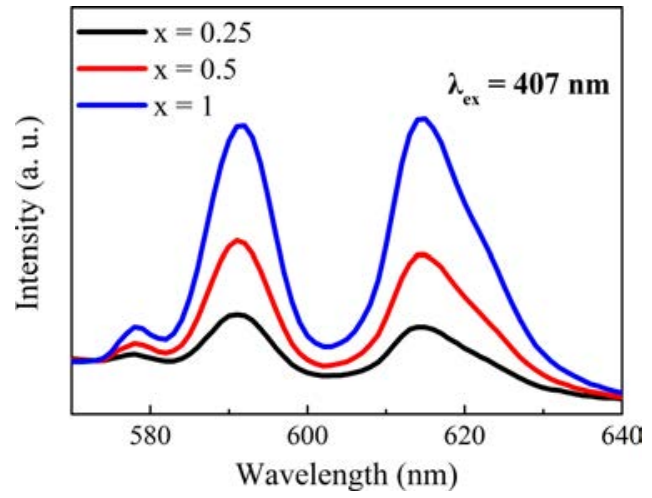

Fig. 7. The PL spectra of the $x$ Eu-KNNBST transparent ceramics with different $\mathrm{Eu}^{3+}$ contents.

vacancies (i.e., $\mathrm{K} / \mathrm{Na} / \mathrm{O}$ vacancies) generated by ion doping. ${ }^{4,18}$ These vacancy-related defect levels locate between the conduction band (CB) and valence band (VB) of the $x \mathrm{Eu}-$ KNNBST ceramics. Under the illumination of xenon lamp, the electron-hole pairs are captured by the defect levels to form color centers, meanwhile the electron-hole pairs are separated. The presence of color centers increases the probability of light scattering, ultimately darkening the color and reducing the optical transmittance of the $x$ Eu-KNNBST ceramics. After thermal stimulus, the trapped electrons absorb enough energy to detach from the holes (such as $\mathrm{O}$ vacancies), resulting in the disappearance of color centers and recovery of ceramic colors. Figure 6(b) shows the optical transmittance spectra before and after the illumination of xenon lamp for $2 \mathrm{~min}$. The observed optical transmittances remarkably decrease ranging from $450 \mathrm{~nm}$ to $800 \mathrm{~nm}$ after illumination. In order to investigate the $\mathrm{PC}$ reaction induced change of $T$ values, the modulation ratio of transmittance $(\triangle \mathrm{Abs})$ is defined as

$$
\Delta \mathrm{Abs}=\frac{T_{0}-T_{1}}{T_{0}} \times 100 \%,
$$

where $T_{0}$ and $T_{1}$ are the transmittance before and after illumination. The $\Delta$ Abs values at $\sim 500 \mathrm{~nm}$ are about $26.2 \%$ $(x=0.25), 18 \% \quad(x=0.5), 22.8 \% \quad(x=1)$, respectively, comparable to that of Er-doped KNLNB transparent ceramics $(28.2 \%){ }^{18}$

\subsection{PL modulations by $P C$ reactions}

Figure 9 shows the PL modulation behavior of the typical sample $x$ Eu-KNNBST with $x=1$. The PL intensity obviously decreases with the extension of time (from $0 \mathrm{~s}$ to $140 \mathrm{~s}$ ). And similar behavior can also be observed in other two samples (i.e., $x=0.25$ and $x=0.5$ ). It can be indicated that the PC behavior not only affects the optical transmittance of sample, but also changes the PL intensity. The mechanism is also related to vacancy-related defects. Upon 407-nm excitation, the luminescence center $\mathrm{Eu}^{3+}$ undergoes ground state transition, multi-phonon relaxation and finally radiation transition (i.e., emission). Due to the existence of the defect levels between $\mathrm{CB}$ and VB in $x \mathrm{Eu}-\mathrm{KNNBST}$, the active electrons of $\mathrm{Eu}^{3+}$ during transition are inevitably captured, decreasing the transition efficiency and then the PL intensity. The emission quenching degree $\left(\Delta R_{t}\right)$ can be well described by the following equation:

$$
\Delta R_{t}=\frac{R_{0}-R_{1}}{R_{0}} \times 100 \%,
$$

where $R_{0}$ and $R_{1}$ is the emission intensity at $615 \mathrm{~nm}$ before and after illumination, respectively. Figure 10 shows the variation of $\Delta R_{t}$ with illumination time for the $x \mathrm{Er}-\mathrm{KNNBST}$

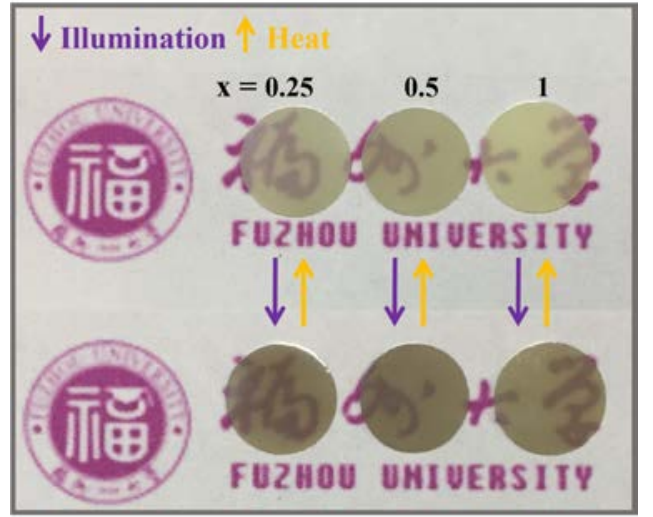

(a)

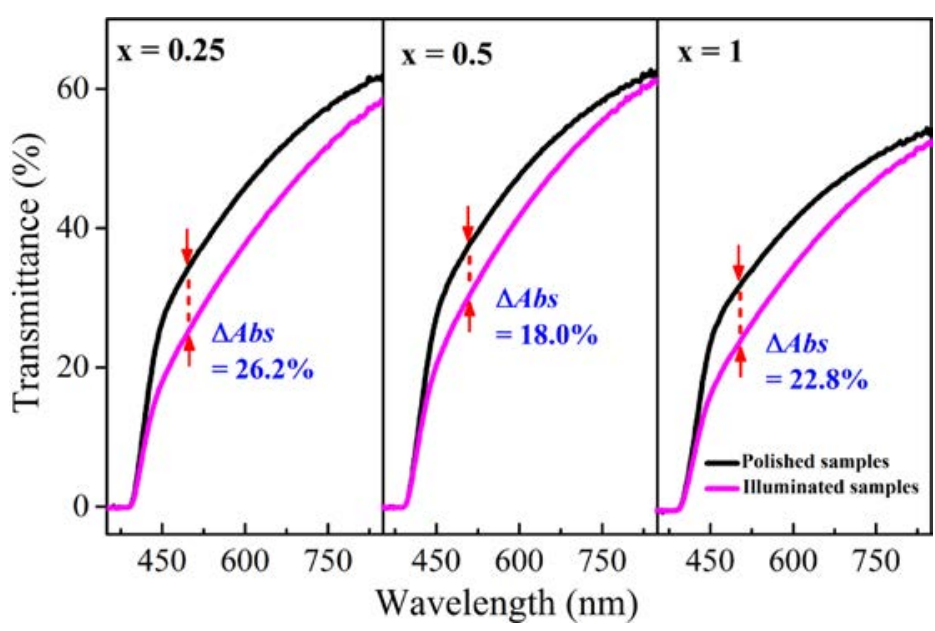

(b)

Fig. 8. Transmittance modulations by PC reactions of the $x$ Eu-KNNBST transparent ceramics. (a) Photographs of the $x$ Eu-KNNBST transparent ceramics under the illumination by xenon lamp $(200-1100 \mathrm{~nm}, 300 \mathrm{~W}, 2 \mathrm{~min})$ and after the thermal stimulus $\left(200^{\circ} \mathrm{C}, 10 \mathrm{~min}\right)$. (b) The optical transmittance spectra of the $x$ Eu-KNNBST transparent ceramics before and after illumination. 


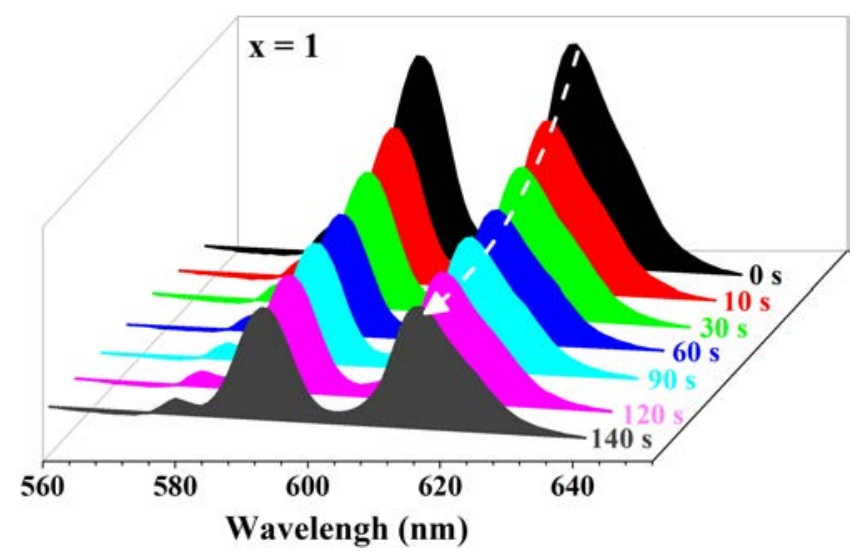

Fig. 9. PL spectral changes of the typical sample $x$ Eu-KNNBST with $x=1$ under the illumination by xenon lamp with different times of $10,30,60,90,120$ and $140 \mathrm{~s}$.

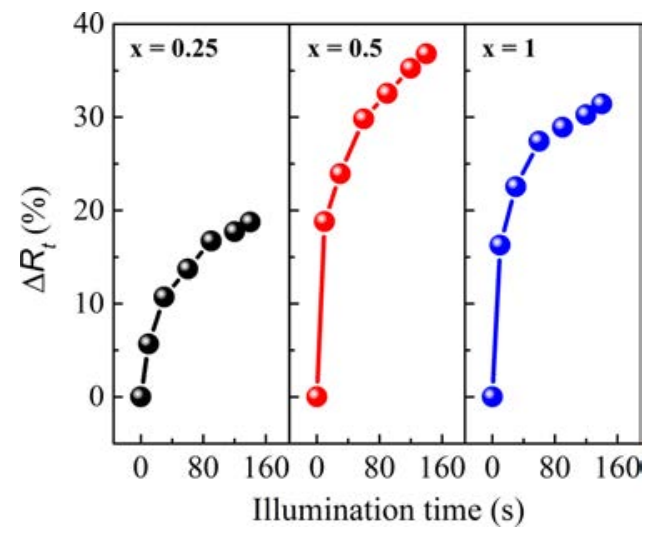

Fig. 10. The variation of luminescence quenching degree $\left(\Delta R_{t}\right)$ with illumination time for the $x \mathrm{Er}-\mathrm{KNNBST}$ transparent ceramics.

transparent ceramics. For the three samples, the $\Delta R_{t}$ values boost sharply from $0 \mathrm{~s}$ to $10 \mathrm{~s}$, and then increase steadily until $140 \mathrm{~s}$, suggesting that the illumination-induced PL quenching is dominating at first $10 \mathrm{~s}$ and then gradually becomes saturated. This PL quenching process is closely linked to the saturation of color centers. At the beginning of first $10 \mathrm{~s}$ illumination, numerous vacancy defects exist and a large number of color centers generate. Correspondingly, the PL intensity decreases rapidly at the first stage. Afterwards, sustained illumination can hardly bring more color centers, leading to the stabilization of PL intensity and saturation of $\Delta R_{t}$ values. At $140 \mathrm{~s}$ of illumination time, the $0.5 \mathrm{Eu}-$ KNNBST ceramic exhibits the maximum $\Delta R_{t}$ value of $\sim 38 \%$, larger than the other two ones ( $\sim 20 \%$ for $x=0.25$ and $\sim 32 \%$ for $x=1$ ). Besides, the PL intensities can also be well restored after the thermal stimulus $\left(200^{\circ} \mathrm{C}, 10 \mathrm{~min}\right)$, similar to the reversible modulation of optical transmittances. The Eu-KNNBST transparent ceramics display outstanding noncontact optical modulations of both transmittance and PL intensity, which have potential in the application of optical sensors and memories.

\section{Conclusions}

The $x$ Eu-KNNBST transparent ceramics were synthesized by the solid-state reaction. The phase structures, microstructures, optical transmittances, densities, ferroelectric properties, PL and photochromism were studied. It is found that the modification of $\mathrm{Eu}^{3+}, \mathrm{Ba}^{2+}, \mathrm{Ti}^{4+}$ and $\mathrm{Sr}^{2+}$ ions in $\mathrm{KNN}$ ceramics can increase the crystal symmetry, reduce the grain size to below $200 \mathrm{~nm}$ and improve the densification. As a result, the ceramics can be made into transparent ones, giving the optical transmittances of $\sim 60 \%$ at $900 \mathrm{~nm}$. Due to the presence of emission center $\mathrm{Eu}^{3+}, x \mathrm{Eu}$-KNNBST shows good downconversion PL characteristics under the excitation of $407 \mathrm{~nm}$. The transmittances and PL intensities can be effectively modulated based on the PC behavior. The photochromism is related to vacancy-related defects caused by ion doping and volatilization of alkali metal ions. The multifunctional $x \mathrm{Eu}-$ KNNBST transparent ceramics enable the superposition of both ferroelectric and optical storages, which further enrich the versatility of KNN-based ferroelectric transparent ceramics and broadens their applications in optoelectronic areas.

\section{Acknowledgments}

This work was supported by the National Natural Science Foundation of China (Nos. 51602055, 51803030, 11874032 and 51602156) and the Natural Science Foundation of Fujian Province (No. 2019J01228).

\section{References}

${ }^{1}$ M. Irie, Diarylethenes for memories and switches, Chem. Rev. 100, 1685 (2000).

${ }^{2}$ Y. Y. Zhang, L. L. Luo, K. X. Li, W. P. Li and Y. F. Hou, Large and reversible in-situ up-conversion photoluminescence modulation based on photochromism via electric-field and thermal stimulus in ferroelectrics, J. Eur. Ceram. Soc. 38, 3154 (2018).

${ }^{3}$ K. X. Li, L. H. Luo, Y. Y. Zhang, W. P. Li and Y. F. Hou, The upconversion luminescence modulation and its enhancement in $\mathrm{Er}^{3+}$-doped $\mathrm{Na}_{0.5} \mathrm{Bi}_{0.5} \mathrm{TiO}_{3}$ based on photochromic reaction, J. Am. Ceram. Soc. 101, 5640 (2018).

${ }^{4}$ H. L. Sun, J. Liu, X. S. Wang, Q. W. Zhang, X. H. Hao and S. L. $\mathrm{An},(\mathrm{K}, \mathrm{Na}) \mathrm{NbO}_{3}$ ferroelectrics: A new class of solid-state photochromic materials with reversible luminescence switching behavior, J. Mater. Chem. C 5, 9080 (2017).

${ }^{5}$ Y. Y. Zhang, L. H. Luo, K. X. Li, W. P. Li and Y. F. Hou, Lightcontrolled reversible photoluminescence modulation in photochromic $\mathrm{Sr}_{2} \mathrm{SnO}_{4}: \mathrm{Eu}^{3+}$, J. Phys. D: Appl. Phys. 51, 365102 (2018).

${ }^{6}$ Q. W. Zhang, H. Sun, H. Li, X. Wang, X. Hao, J. Song and S. An, Reversible photoresponsive switching in $\mathrm{Bi}_{2.5} \mathrm{Na}_{0.5} \mathrm{Nb}_{2} \mathrm{O}_{9}$-based luminescent ferroelectrics, Chem. Commun. 51, 16316 (2015).

${ }^{7}$ J. Liu, Y. Zhang, H. Q. Sun, Q. W. Zhang, X. S. Wang and X. H. Hao, Reversible up-conversion emission and photo-switching properties in Er doped (K,Na) $\mathrm{NbO}_{3}$ ferroelectrics, J. Lumin. 207, 85 (2019). 
${ }^{8}$ X. Qiao, X. Zhang, D. Wu, X. Chao and Z. Yang, Influence of Bi nonstoichiometry on the energy storage properties of $0.93 \mathrm{KNN}$ $0.07 \mathrm{Bi}_{x} \mathrm{MN}$ relaxor ferroelectrics, J. Adv. Dielect. 8, 1830006 (2018).

${ }^{9}$ P. Kumari, M. Lal, S. Kumar, R. Rai, A. Singh, D. V. Karpinsky and I. Bdikin, Comprehensive investigation of structural, dielectric and local piezoelectric properties of KNN ceramics, J. Adv. Dielect. 9, 1950016 (2019).

${ }^{10}$ P. Li, J. W. Zhai, B. Shen, S. J. Zhang, X. L. Li, F. Y. Zhu and X. M. Zhang, Ultrahigh piezoelectric properties in textured (K, Na)$\mathrm{NbO}_{3}$-based lead-free ceramics, Adv. Mater. 30, 1705171 (2018).

${ }^{11} \mathrm{~K}$. Wang and J. F. Li, Domain engineering of lead-free Li-modified $(\mathrm{K}, \mathrm{Na}) \mathrm{NbO}_{3}$ polycrystals with highly enhanced piezoelectricity, Adv. Funct. Mater. 20, 1924 (2010).

${ }^{12}$ K. Xu, J. Li, X. Lv, J. G. Wu, X. X. Zhang, D. Q. Xiao and J. G. Zhu, Superior piezoelectric properties in potassium-sodium niobate lead-free ceramics, Adv. Mater. 28, 8519 (2016).

${ }^{13}$ K. X. Li, L. H. Luo, Y. Y. Zhang, W. P. Li and Y. F. Hou, Tunable luminescence contrast in photochromic ceramics (1-x)$\mathrm{Na}_{0.5} \mathrm{Bi}_{0.5} \mathrm{TiO}_{3}-\mathrm{xNa}_{0.5} \mathrm{~K}_{0.5} \mathrm{NbO}_{3}: 0.002 \mathrm{Er}$ by an electric field poling, ACS Appl. Mater. Inter. 10, 41525 (2018).

${ }^{14}$ J. F. Lin, Q. L. Lu, J. Xu, X. Wu, C. Lin, T. F. Lin, C. Chen and L. L. Luo, Outstanding optical temperature sensitivity and dualmode temperature-dependent photoluminescence in $\mathrm{Ho}^{3+}$-doped (K,Na) $\mathrm{NbO}_{3}-\mathrm{SrTiO}_{3}$ transparent ceramics, J. Am. Ceram. Soc. 102, 4710 (2019).

${ }^{15}$ B. K. Wang, X. X. Tian, Z. X. Zhuo, S. B. Qu and Z. R. Li, Preparation and performances of KNN-based lead-free transparent ceramics, Acta. Phys. Sin. 61, 197703 (2012).

${ }^{16}$ F. L. Li and K. W. Kwok, Fabrication of transparent electro-optic $\left(\mathrm{K}_{0.5} \mathrm{Na}_{0.5}\right)_{1-x} \mathrm{Li}_{x} \mathrm{Nb}_{1-x} \mathrm{Bi}_{x} \mathrm{O}_{3}$ lead-free ceramics, J. Eur. Ceram. Soc. 33, 123 (2013).

${ }^{17}$ Z. Y. Liu, H. Q. Fan, Y. W. Zhao and G. Z. Dong, Optical and tunable dielectric properties of $\mathrm{K}_{0.5} \mathrm{Na}_{0.5} \mathrm{NbO}_{3}-\mathrm{SrTiO}_{3}$ ceramics, J. Am. Ceram. Soc. 99, 146 (2016).
${ }^{18}$ H. Q. Sun, Y. Lv, Y. Zhu, J. F. Lin, X. Wu, Q. W. Zhang and X. H. Hao, Photochromism-induced light scattering and photoswithing in Er doped (K,Na) $\mathrm{NbO}_{3}$ transparent ceramics, J. Am. Ceram. Soc. in press (2019).

${ }^{19}$ X. M. Zhao, Q. Z. Chai, B. Chen, X. L. Chao and Z. P. Yang, Improved transmittance and ferroelectric properties realized in KNN ceramics via SAN modification, J. Am. Ceram. Soc. 101, 5127 (2018).

${ }^{20}$ X. S. Zhang, D. Yang, Z. Y. Yang, X. M. Zhao, Q. Z. Chai, X. L. Chao, L. L. Wei and Z. P. Yang, Transparency of $\mathrm{K}_{0.5} \mathrm{Na}_{0.5} \mathrm{NbO}_{3^{-}}$ $\mathrm{Sr}\left(\mathrm{Mg}_{1 / 3} \mathrm{Nb}_{2 / 3}\right) \mathrm{O}_{3}$ lead-free ceramics modulated by relaxor behavior and grain size, Ceram. Int. 42, 17963 (2016).

${ }^{21}$ J. Li, J. W. Dai and Y. B. Pan, Research progress on magnetooptical transparent ceramics, J. Inorg. Mater. 33, 1 (2018).

${ }^{22}$ J. Z. Ma, H. Y. Li, H. J. Wang, C. Lin, X. Wu, T. F. Lin, X. H. Zheng and $\mathrm{X}$. $\mathrm{Yu}$, Composition, microstructure and electrical properties of $\mathrm{K}_{0.5} \mathrm{Na}_{0.5} \mathrm{NbO}_{3}$ ceramics fabricated by cold sintering assisted sintering, J. Eur. Ceram. Soc. 39, 986 (2019).

${ }^{23}$ L. Q. Cheng, K. Wang, F. Z. Yao, F. Y. Zhu and J. F. Li, Composition inhomogeneity due to alkaline volatilization in Li-Modified (K,Na) $\mathrm{NbO}_{3}$ lead-free piezoceramics, J. Am. Ceram. Soc. 96, 2693 (2013).

${ }^{24}$ Y. Zhang, J. Liu, H. Q. Sun, D. F. Peng, R. H. Li, C. K. Bulin, X. S. Wang, Q. W. Zhang and X. H. Hao, Reversible luminescence modulation of Ho-doped $\mathrm{K}_{0.5} \mathrm{Na}_{0.5} \mathrm{NbO}_{3}$ piezoelectrics with high luminescence contrast, J. Am. Ceram. Soc. 101, 2305 (2018).

${ }^{25}$ X. Wu, M. L. Chi and K. W. Kwok. Effect of phase transition on photoluminescence of Er-doped KNN ceramics, J. Lumin. 155, 343 (2014).

${ }^{26}$ Y. Dong, Z. Y. Yang, X. S. Zhang, L. L. Wei, X. L. Chao and Z. P. Yang, High transmittance in lead-free lanthanum modified potassium-sodium niobate ceramics, J. Alloys Compd. 716, 21 (2017).

${ }^{27}$ Z. M. Geng, K. Li, X. Li and D. Shi, Fabrication and photoluminescence of Eu-doped KNN-based transparent ceramics, J. Mater. Sci. 52, 2285 (2017). 